A 52-year-old woman was admitted to our institute with abdominal pain in the right upper quadrant and anorexia for a few days. In 1995, she had undergone a lithotripsy using percutaneous cholangioscopy, because of intrahepatic bile duct stones. The patient had refused resection of the left lateral segment of the liver. A self-expandable metal stent covered with polytetrafluoethylene had also been inserted in the stricture site in the left main intrahepatic bile duct, to avoid recurrent cholangitis and intrahepatic bile duct stone. Now, 6 years later, she had developed abdominal pain in the right upper quadrant associated with an elevated serum level of aminotransferase and alkaline phosphatase (aspartate aminotransferase $56 \mathrm{IU} / 1$ (normal range 0 $37 \mathrm{IU} / \mathrm{l}$ ); alanine aminotransferase $45 \mathrm{IU} / 1$ (normal range $0-41 \mathrm{IU} / 1$ ); alkaline phosphatase $643 \mathrm{IU} / 1$ (normal range 53$128 \mathrm{IU} / 1)$. Endoscopic retrograde cholangiopancreatography revealed the dilated extrahepatic bile duct and left intrahepatic bile duct to be without stricture, and also the presence in the distal common bile duct of a large elongated freely mobile filling defect, suggestive of common bile duct stone containing a metal mesh (Figure 1). After successful endoscopic sphincterotomy, mechanical lithotripsy

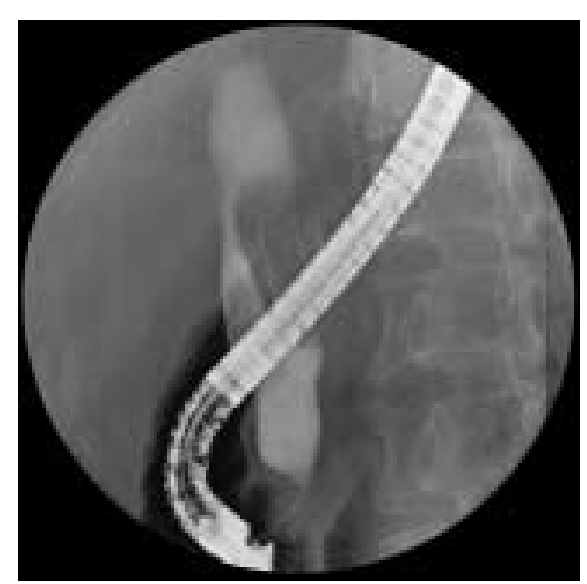

Figure 1 Endoscopic retrograde cholangiopancreatography (ERCP) demonstrated dilated extrahepatic bile and left intrahepatic bile ducts. Note the large elongated filling defect with the metal stent centrally in the extrahepatic bile duct.

\title{
Endoscopic Management of Choledocholithiasis Resulting from a Biliary Metal Stent
}

was performed because of the large size of the stone. The stone was soft and dark brown in color with the metal stent extruding from the ampulla of Vater along with common bile duct stone fragments (Figure 2). After complete removal of the stone, the serum level of hepatic enzymes returned to normal, and the patient has remained asymptomatic. An intrahepatic biliary stricture may not only limit the clearance of stones but also contribute to the recurrence of stones and cholangitis. Published reports of the intrahepatic use of metallic stents for hepatolithiasis and biliary stricture remain limited. Jeng et al. [1] reported that metallic stent placement seemed to be an effective and welltolerated treatment for complicated refractory hepatic ductal strictures with hepatolithiasis. The formation of biliary tract stones around surgically introduced foreign material has been well documented. IT is reported that $30 \%$ of recurrent stones after cholecystectomy contained nonabsorbable suture material in their nuclei [2]. Metallic surgical clips have migrated into the biliary tract and acted as a nidus for stone formation $[3,4]$. Biliary stasis and bacterial overgrowth resulting in bacterial degradation of bile were contributing factors in the above cases [5].

\section{Y. K. Cheon, J. H. Moon, Y. D. Cho, M. S. Lee, C. S. Shim}

Institute for Digestive Research, Digestive Disease Center, College of Medicine, Soon Chun Hyang University, Seoul, Korea.

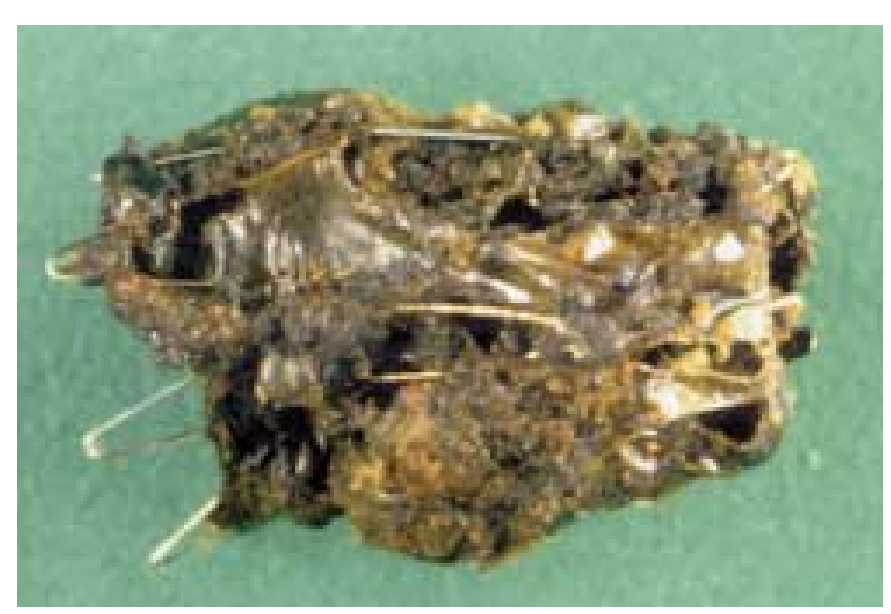

\section{References}

${ }^{1}$ Jeng KS, Sheen IS, Yang FS et al. Percutaneous transhepatic placement of metallic stents in the treatment of complicated intrahepatic biliary stricture with hepatolithiasis: a preliminary report. Am J Gastroenterol 1999; 94: $3507-$ 3512

${ }^{2}$ Whiting MJ, Watts JM. Chemical composition of common bile duct stones. Br J Surg 1986; 73: 229-232

${ }^{3}$ Brutvan FM, Kampshroer BH, Parker HW. Vessel clip as a nidus for formation of common bile duct stone. Gastrointest Endosc 1982; 28: 222-223

${ }^{4}$ Shibata S, Okumichi T, Nishimura Y et al. A case of choledocholithiasis with an endoclip nidus, 6 months after laparoscopic cholecystectomy. Surg Endosc 1996; 10: 1097-1098

${ }^{5}$ Thistle JL. Pathophysiology of bile duct stones. World J Surg 1998; 22: $1114-$ 1118

\section{Corresponding Author}

\section{S. Shim, M.D.}

Institute for Digestive Research

College of Medicine

Soon Chun Hyang University Hospital

657 Hannam-Dong, Youngsan-Ku

Seoul 140-743, Korea

Fax: $\quad+82-2-7491968$

E-mail: schidr@hosp.sch.ac.kr
Figure 2 The exposed area of metallic stent with the conglomerated fragments of stone, and the distorted covered area of the stent with polytetrafluoethylene material, after washing. 